\title{
The genus Thoradonta in Thailand (Orthoptera: Tetrigidae: Scelimeninae) with description of two new species
}

\author{
Ling-Sheng Zha (10) ${ }^{\mathrm{a}, \mathrm{b}, \mathrm{c}}$, Ting-Chi Wen (10) ${ }^{\mathrm{a}}$, Ji-Chuan Kang ${ }^{\mathrm{a}}$ and Kevin D. Hyde $\mathrm{e}^{\mathrm{a}, \mathrm{c}}$
}

aThe Engineering and Research Centre for Southwest Bio-Pharmaceutical Resources of National Education Ministry of China, Guizhou University, Guiyang, China; ${ }^{b}$ School of Life Sciences, Huaibei Normal University, Huaibei, China; 'Institute of Excellence in Fungal Research, and School of Science, Mae Fah Luang University, Chiang Rai, Thailand

\begin{abstract}
The genus Thoradonta Hancock (Orthoptera: Tetrigidae: Scelimeninae) is newly reported from Thailand. Two new species of the genus, Thoradonta lativertexoides sp. nov. and Thoradonta spiculobaoides sp. nov., are described and illustrated with photographs and compared with similar species. A taxonomic review of the genus Thoradonta is provided and a key to all known species of the genus is given.
\end{abstract}

\section{ARTICLE HISTORY}

Received 8 April 2015

Accepted 2 September 2015

Online 10 December 2015

\section{KEYWORDS}

Diversity; distribution; taxonomy; newly recorded genus; Chiang Rai

\section{Introduction}

The family Tetrigidae (or the superfamily Tetrigoidea: Orthoptera: Insecta) currently comprise 1828 accepted species and 83 accepted infraspecific names (some species published in 2015 are not included, http://www.gbif.org/species), and they can be found worldwide except for the polar regions.

The genus Thoradonta (Tetrigidae: Scelimeninae) was erected by Hancock in 1909 who designated Thoradonta dentata Hancock, 1909 as the type species. It includes 19 known species worldwide, which are distributed in countries of subtropical and tropical Asia and equinoctial Africa (Hancock 1909, 1915; Günther 1938; Blackith and Blackith 1987; Shishodia 1991; Zheng and Liang 1991; Podgornaya 1994; Ingrisch 2001; Zheng 2005; Deng et al. 2006).

In this study we report the genus Thoradonta Hancock as new for Thailand. Two new species, Thoradonta lativertexoides Zha and Kang sp. nov. and Thoradonta spiculobaoides Zha and Kang sp. nov., are introduced with descriptions and illustrations and compared with similar taxa. We also provide a taxonomic review of the genus Thoradonta. A key to all known species of the genus is given. 


\section{Material and methods}

Specimens were examined and photographed using a stereomicroscope (Olympus Corporation, SZX16, Tokyo, Japan). Morphological terminology and measurement landmarks follow Zheng (2005). Measurements are given in millimetres. Holotypes are deposited in the herbarium of Mae Fah Luang University (MFLU), Chiang Rai, Thailand, paratypes in both MFLU and the Specimen Room of the School of Life Sciences, Huaibei Normal University (HNU), Huaibei, Anhui, China.

\section{Genus Thoradonta Hancock, 1909}

new for Thailand

Hancock, 1909, Trans. Entomol. Soc. London, p. 407; Günther, 1938, Stettiner Entomologische Zeitung, 99: p. 121; Zheng and Liang, 1991, Acta Entomologica Sinica 34(4): p. 453; Liang and Zheng, 1998, Fauna Sinica, Insecta, vol. 12, Orth., Tetrigoidea, p. 56; Zheng, 2005, Fauna of Tetigoidea from western China, p. 59; Deng, Zheng and Wei, 2007, Fauna of the Tetrigoidea from Yunnan and Guangxi, p. 51.

\section{Type species}

Thoradonta dentata Hancock, 1909

\section{Generic characteristics (updated)}

Body size small, vertex equal to or wider than one eye, frontal ridge distinctly protruding between antennae. Antennae filiform, inserted between or below lower anterior margins of eyes. Eyes globular and prominent, lateral ocellus situated in or slightly below middle of anterior margin of eye. Distal segments of maxillary palpus slightly compressed. Pronotal disc covered with many nodules; mid-keel undulate, partially lamellate and erected before shoulders; pronotum slightly uplifted between shoulders; a pair of abbreviated carinae present between shoulders; hind process of pronotum wedgeshaped, not reaching, reaching or surpassing beyond apex of hind femur; posterior angle of lateral lobe of pronotum distinctly laminate and expanded, apex spine-like or acute dentate and extending transversely or obliquely backward, but few species truncate or subtruncate. Tegmina ovate, hindwing present or absent (Thoradonta butlini). First segment of hind tarsus generally longer than third.

\section{Relationship to other genera}

The genus Thoradonta Hancock was placed in Scelimeninae (Tetrigidae) based on: (1) filiform antenna; (2) in profile frontal ridge protruding in arch-like manner between base of antennae; (3) posterior angle of lateral lobe of pronotum lamellate and expanded, apex generally spine-like.

The genus Thoradonta is closely related to the genus Criotettix Bolivar, 1887, the former differs from the latter mainly by: (1) lateral margins of pronotum behind humeral angles distinctly folded upwards; (2) partial mid-keel lamellate and erected before shoulders. 


\section{Key to species of the genus Thoradonta Hancock}

1. Tegmen and wing absent. Distributed in Indonesia .. T. butlini Blackith and Blackith Tegmina and wings present.

2. Apex of posterior angle of lateral lobe of pronotum truncate or slightly convex, not spined.

Apex of posterior angle of lateral lobe of pronotum spined.

3. Body size large, hind process of pronotum surpassing far beyond apex of hind femur. Distributed in Nepal..

T. aspinosa Ingrisch Body size small, hind process of pronotum shorter, only reaching apex of hind femur. Distributed in China.

T. obtusilobata Zheng

4. Hind process of pronotum shorter, not reaching or reaching apex of hind femur 5 Hind process of pronotum longer, surpassing beyond apex of hind femur............ 8

5. Hind process reaching apex of hind femur; lower lobe of posterior angle of pronotum distinct and acute. Distributed in India, Bengal . T. bengalensis Shishodia Hind process not reaching apex of hind femur; lower lobe of posterior angle of pronotum indistinct or obtuse.

6. Wings shorter, not reaching apex of hind process; third pulvillus of first segment of hind tarsus longer than second. Distributed in: China, Hong Kong, India, Indonesia, Malaysia, Singapore, Sri Lanka. T. nodulosa (Stål) Wings longer, reaching apex of hind process; third pulvillus of first segment of hind tarsus equal to second in length.

7. Lateral lobes of pronotum with posterior angles obliquely dentate. Distributed in Malaysia. T. dentata Hancock Lateral lobes of pronotum with posterior angles acute spinose, spine transverse. Distributed in equinoctial Africa. T. spinata Hancock

8. Body size stout; hind process of pronotum surpassing slightly beyond apex of hind femur

Body size slender; hind process of pronotum surpassing far beyond apex of hind femur.

9. Anterior margin of vertex nearly as wide as posterior margin; spine of posterior angle of lateral lobe of pronotum extending distinctly obliquely backward. Distributed in China T. yunnana Zheng Anterior margin of vertex distinctly narrower than posterior margin; spine of posterior angle of lateral lobe of pronotum extending transversely or slightly obliquely backward 10

10. Spine very long; wings reaching apex of hind process of pronotum. Distributed in China T. longispina Zheng and Xie Spine shorter; wings not reaching apex of hind process of pronotum. 
11. Antenna inserted between lower margins of eyes, length of longest segment four times its width; first segment of hind tarsus 1.75 times as long as third. Distributed in China, India. T. spiculoba Hancock Antenna inserted decidedly below lower margins of eyes, length of longest segment six times its width; first segment of hind tarsus only 1.3-1.4 times as long as third. Distributed in Thailand;

T. spiculobaoides sp. nov.

12. Spine of posterior angle of lateral lobe of pronotum pointing laterally 13 Spine of posterior angle of lateral lobe of pronotum pointing obliquely backward.

13. Vertex 2.0 times as wide as one eye; wings not reaching apex of hind process. Distributed in India, Vietnam. $T$. centropleura Podgornaya Vertex not more than 1.5 times as wide as one eye; wings reaching or surpassing beyond apex of hind process.

14. Spine slender; length of pronotum 2.4-3.0 times as long as length of hind process which is beyond hind femora; wings surpassing apex of hind process. Distributed in China T. longipenna Zheng and Liang Spine shorter; length of pronotum 3.3-4.0 times as long as length of hind process which is beyond hind femora; wings reaching apex of hind process. Distributed in China. T. transspicula Zheng

15. Vertex wider, 1.5-2.0 times as wide as one eye. 16

Vertex narrower, 1.18-1.35 times as wide as one eye. 20

16. Wings longer, surpassing far beyond apex of hind process; disc of pronotum black. Distributed in China T. nigrodorsalis Zheng and Liang Wings shorter, not reaching or surpassing slightly beyond apex of hind process; pronotum and body in the same colour

17. Length of pronotum not less than 5.0 times as long as hind process which is beyond apex of hind femur

Length of pronotum not more than 4.0 times as long as hind process which is beyond apex of hind femur

18. Lateral keels parallel; wings not reaching apex of hind process. Distributed in China T. lancangensis Zheng Lateral keels distinctly contracted backward; wings surpassing apex of hind process. Distributed in: China. T. dianguiensis Deng, Zheng and Wei

19. Antenna inserted between lower margins of eyes; lateral keels parallel; mid-keel complete between two highest lamellate protrusions; humeral angle widely rounded. Distributed in China, India.. T. lativertex Günther Antenna inserted decidedly below lower margins of eyes; lateral keels distinctly contracted backward; mid-keel interrupted between two highest lamellate protrusions; humeral angle obtuse angled. Distributed in Thailand. 
20. Vertex 1.25-1.35 times as wide as one eye; body surface smooth; length of hind process which is beyond apex of hind femur 3.0-3.4 $\mathrm{mm}$. Distributed in Philippines T. palawanica Günther Vertex nearly equal to one eye in width; body surface coarsely; length of hind process which is beyond apex of hind femur 1.5-2.0 $\mathrm{mm}$. Distributed in India, China T. apiculata Hancock

\section{Species of the genus Thoradonta Hancock in Thailand}

Thoradonta lativertexoides Zha and Kang sp. nov.

(Figures 1A, B, 2A-D)

\section{Male}

Body size small, covered with numerous small granules and many nodules (Figure 1A, B). Head not protruding over level of pronotal surface; vertex about 2.0 times one eye in width, anterior margin straight, protruding forwards to same level of anterior margins of eyes, lateral margins folded upwards but not surpassing beyond top of eyes (Figures 1B, 2B); median carina conspicuous and protruding in anterior half, which is visible before eyes in profile, while obscure or absent in posterior half; vertex and frontal ridge roundly protruding, excessively concave between lateral ocelli, and then excessively protruding in an arch-like manner between antennae, longitudinal furrow slightly wider than first

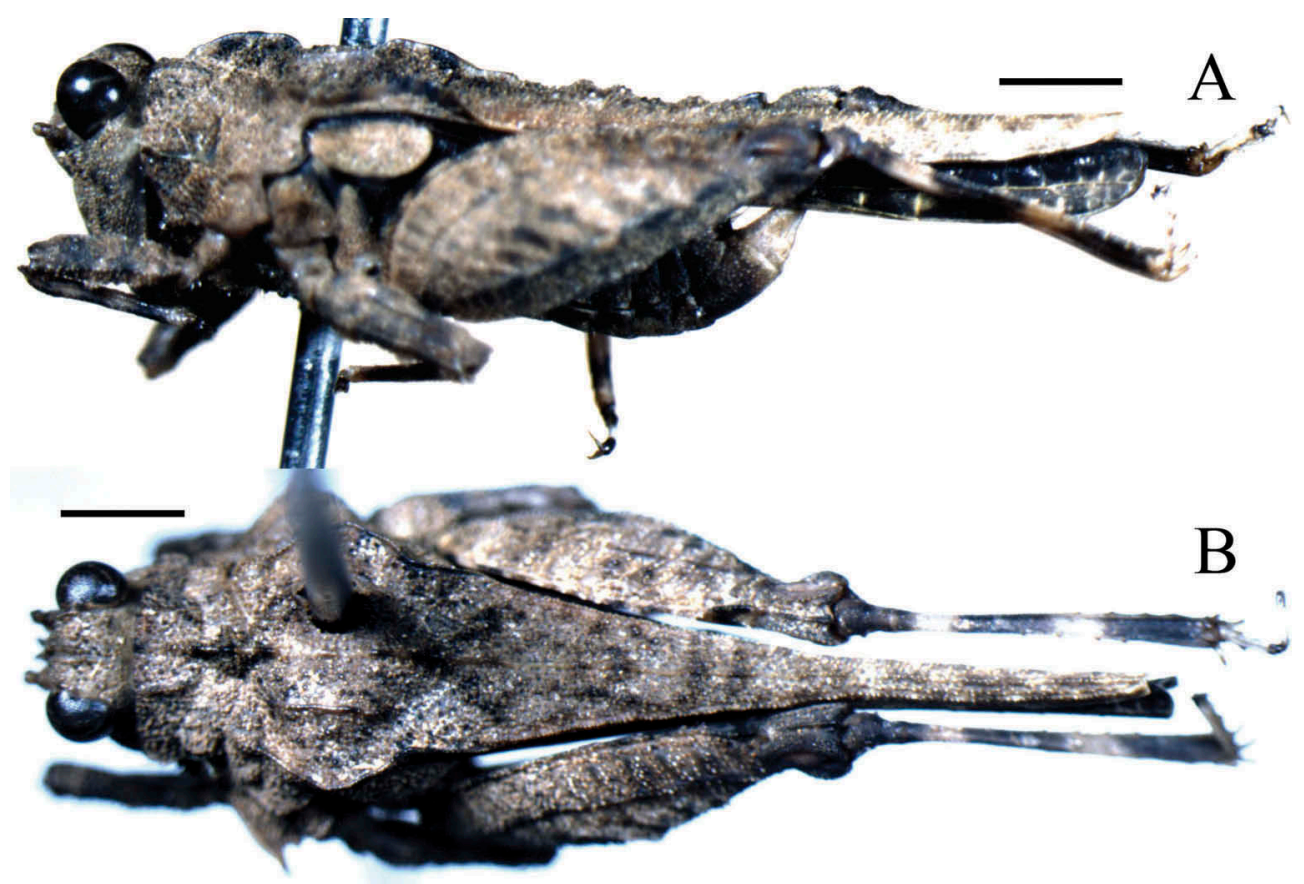

Figure 1. (A, B) Thoradonta lativertexoides sp. nov. male: lateral and dorsal views of body (scale bar $1 \mathrm{~mm})$. 

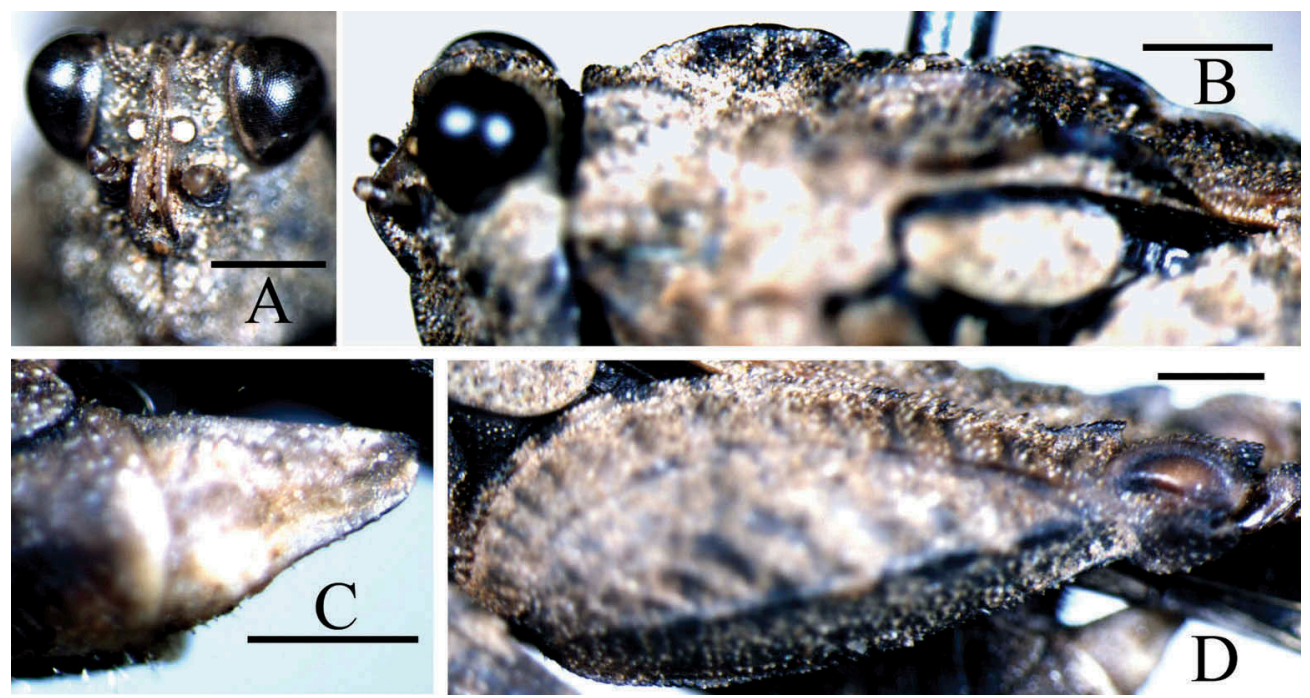

Figure 2. (A-D) Thoradonta lativertexoides sp. nov. male. (A) Frontal view of head; (B) lateral view of head and anterior pronotum; (C) oblique-lateral view of subgenital plate; (D) lateral view of hind femur (scale bar $0.5 \mathrm{~mm}$ ).

segment of antenna in width (Figure 2A). Antenna filiform, 15-segmented, inserted slightly below lower margins of eyes, length of longest segment (segment IV) about six times its width. Eyes globose, protruding but not above level of pronotum (Figure 2B); lateral ocellus situated slightly below middle of anterior margin of eye (Figure 2A). Pronotum very coarse, covered with numerous small granules and many nodules; anterior margin straight, lateral keels erected, contracted backward, sometimes undulate in lateral view. Mid-keel not reaching anterior margin of pronotum, interrupted before shoulders, in profile upper margin distinctly undulate. These sinusoidal waves lamellate and erected, first highest, with intumesced base, both sides of intumescence with a pair of big nodules at margins of pronotum; second lamella very short and low; third lamella longest and undulate, its peak nearly of same height as first; on both sides pronotal disc distinctly concave followed by a pair of long oblique nodules, and lateral margins of pronotum distinctly folded upwards; the latter lamellae becoming lower backward and disappearing on distal part, three or four lamellae are visible and they connect with nodules of both their sides, respectively (Figure 1A, B). Humeral angle obtuse, with a pair of abbreviated carinae between shoulders, pronotum slightly uplifted between shoulders (Figure 1B); hind process of pronotum long cone-shaped, nearly reaching top of hind tibia, apex truncate (Figure 1A, B); posterior angles of lateral lobes of pronotum extending outwards, distal part slightly oblique backward, fore margin of posterior angle smooth while hind margin with small teeth, apex spine-like; posterior margin of each lateral lobe with two concavities. Tegmina ovate, 2.2 times as long as wide, apex rounded. Hindwing surpassing slightly beyond top of hind process of pronotum. Upper and lower margins of fore and mid femora undulate, with fine teeth; 
width of basal mid femur slightly wider than width of tegmen, middle femur distinctly narrowed from basal to distal side, and basal part thicker than distal part. Hind femur about 2.6 times as long as wide, upper and lower margins dentate, outer side and upper side with a series of nodules respectively; upper margin with a triangular protrusion before antegenicular, antegenicular isolated and long triangular, its apex nearly rightangled, genicular denticle fingered extending backward and apex triangular (Figure 2D). Width of distal hind tibia slightly wider than basal, outer side with four to six spines, inner side with four spines; first segment of hind tarsus about 1.3 times longer than third, third pulvillus longer than first and second, apices of all pulvilli sharp. Subgenital plate short cone-shaped (Figure 2C), apex bifurcate and bidentate.

Body dark brown. Antenna brown and colour of distal segments darker; hindwings black; fore and mid femora and tibiae with three yellowish brown bands, bands of femora obscure; lower outside of hind femur black, centre of inner side of hind femur dark brown; hind tibia with two long yellowish brown bands.

\section{Female}

Unknown.

\section{Measurements}

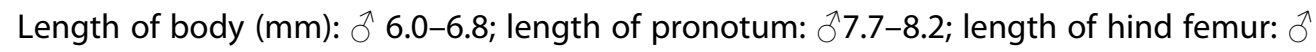
4.0-4.2.

\section{Type material}

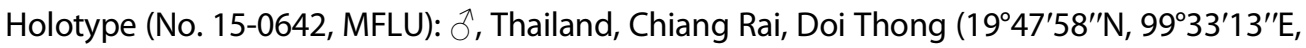
$1234.7 \mathrm{~m}$ altitude), 8 November 2014, collected by ZHA Ling-Sheng. Paratypes: $1 \sigma^{\Uparrow}$ (No. 15-0643, MFLU) and $1 \hat{\jmath}(\mathrm{HNU})$, same data as holotype.

\section{Diagnosis}

Thoradonta lativertexoides sp. nov. is similar to T. lativertex Günther, 1938, but it differs in: (1) antenna inserted decidedly below lower margins of eyes (Figure 2A); (2) lateral keels distinctly contracted backward (Figure 1B); (3) a short and lower lamellate protrusion present between two highest lamellate protrusions on mid-keel, mid-keel interrupted before this short protrusion (Figure 1B); (4) humeral angle obtuse angled (Figure 1B); (5) upper margin of hind femur with a triangular protrusion before antegenicular, antegenicular isolated and long triangular (Figure 2D).

\section{Etymology}

The new species epithet is derived from Thoradonta lativertex, which means it is similar to that species.

\section{Distribution}

Thailand (Chiang Rai). 
Thoradonta spiculobaoides Zha and Kang sp. nov.

(Figures 3A-C, 4A-F, 5A-D)

\section{Male}

Body size small, covered with numerous small granules and many nodules (Figure 3A-B). Head not protruding over level of pronotal surface; vertex 1.5-1.6 times as wide as one eye, anterior margin straight, protruding but not surpassing anterior margins of eyes,

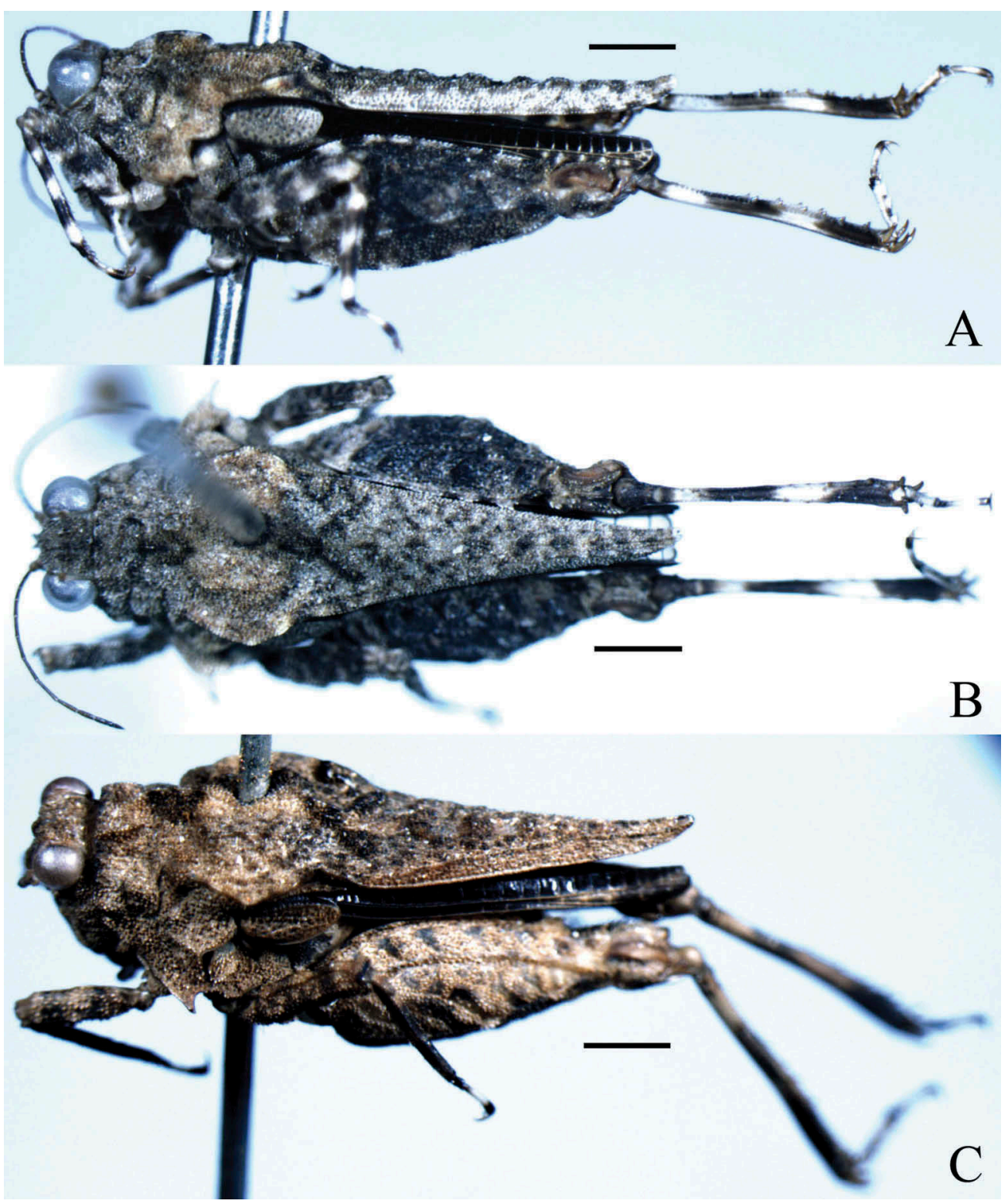

Figure 3. (A-C) Thoradonta spiculobaoides sp. nov.: (A, B) lateral and dorsal views of male body; (C) oblique view of female body (scale bar $1 \mathrm{~mm}$ ). 

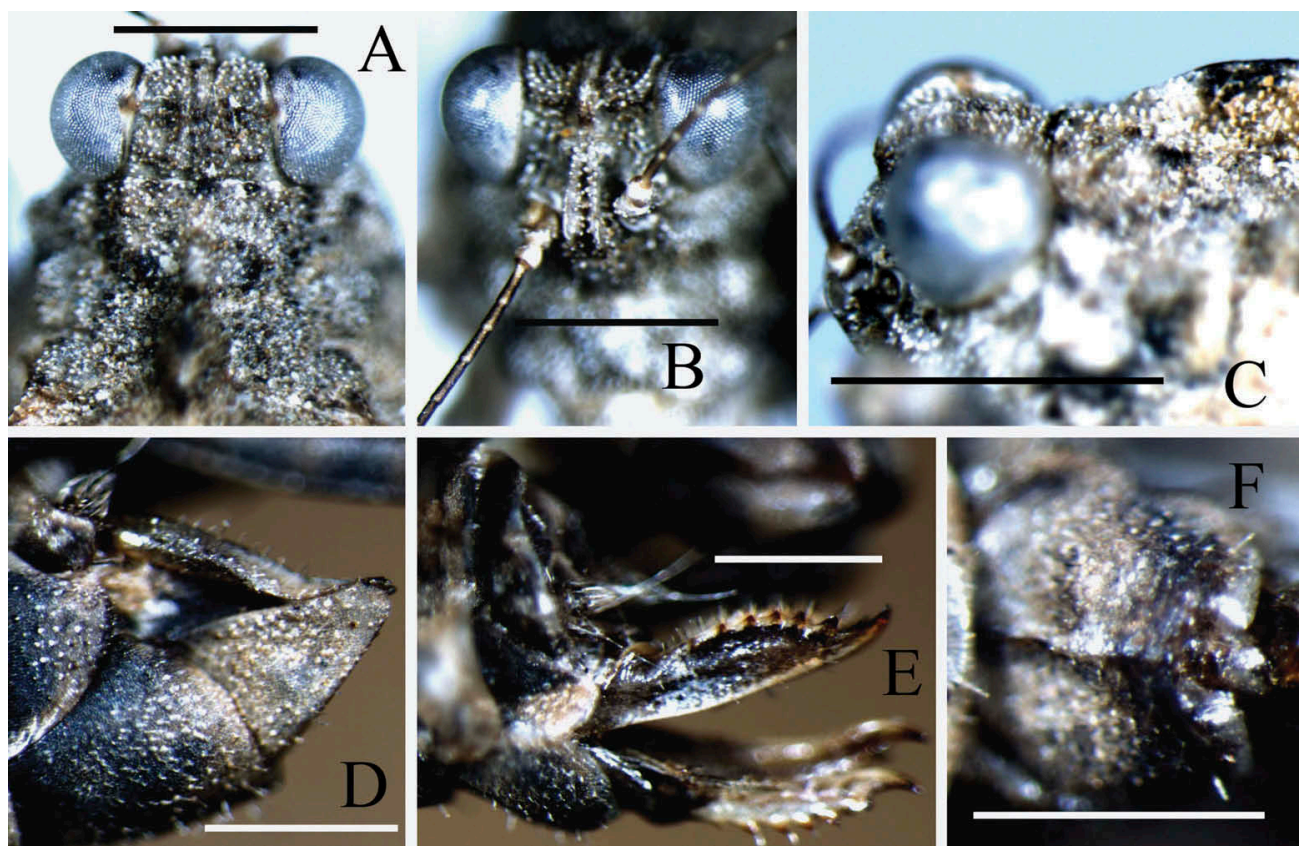

Figure 4. (A-F) Thoradonta spiculobaoides sp. nov.: (A) dorsal view of male head and anterior pronotum; (B) frontal view of male head; (C) lateral view of male head; (D) oblique-dorsal view of male subgenital plate; $(E)$ lateral view of female ovipositor; $(F)$ ventral view of female subgenital plate (scale bar $1 \mathrm{~mm}$ ).
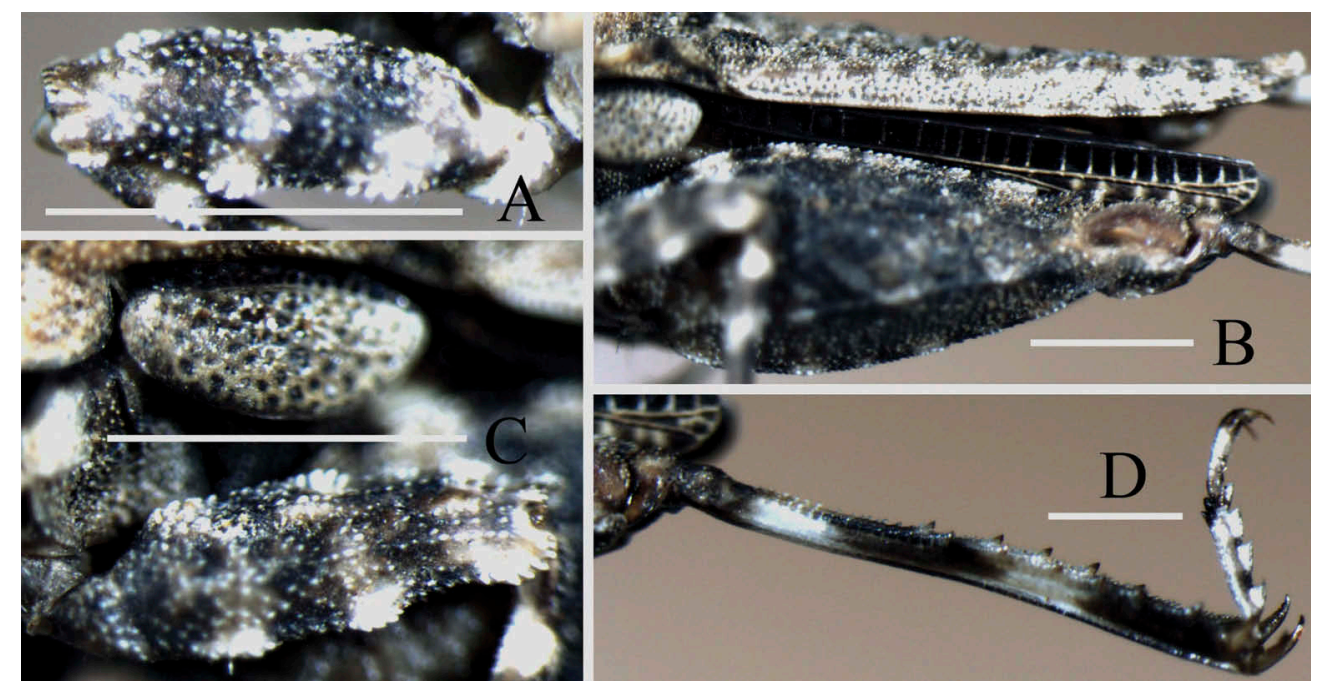

Figure 5. (A-D) Thoradonta spiculobaoides sp. nov. male: (A) lateral view of fore femur; (B) lateral view of hind femur; (C) lateral view of tegmen and mid femur; (D) lateral view of hind tibia (scale bar $1 \mathrm{~mm})$.

lateral margins folded upwards but not surpassing top of eyes (Figure 4A, C); median carina conspicuous and protruding in anterior half which is visible before eyes in profile, while obscure or absent in posterior half; vertex and frontal ridge roundly protruding, 
excessively concave between lateral ocelli, and then excessively archedly protruding between antennae, longitudinal furrow about as wide as first segment of antenna (Figure 4B). Antenna filiform, 15-segmented, inserted slightly below lower margins of eyes (Figure 4B), length of longest segment (segment IV) about six times its width. Eyes globose, protruding but not above level of pronotum; lateral ocellus situated slightly below middle of anterior margin of eye. Pronotum very coarse, covered with numerous small granules and many nodules; anterior margin straight, lateral keels erected, slightly contracted backward, sometimes interrupted in middle or distal part excessively contracted inward (Figure 4A). Mid-keel not reaching anterior margin of pronotum, otherwise nearly complete, in profile upper margin distinctly undulate with wave peaks becoming lower backward and disappearing in distal area. These sinusoidal waves lamellate and erected, first highest, with intumesced base, both sides of intumescence with a pair of big nodules at margins of pronotum; second lamella longest and undulate, on both sides pronotal disc distinctly concave followed by a pair of long oblique nodules, and lateral margins of pronotum distinctly folded upwards; the latter mid-keel with about seven or eight lamellae, no less than four are visible and they connect with nodules of both their sides respectively (Figure 3A, B). Humeral angle obtusely angled, with a pair of abbreviated carinae between shoulders, pronotum slightly uplifted between shoulders (Figure 3A, B); hind process of pronotum long cone-shaped, surpassing slightly beyond top hind femora, distal part slightly upcurved and apex truncate (Figure 3A, B); posterior angles of lateral lobes of pronotum extending outwards, distal part nearly transverse or slightly oblique backward, fore margin of posterior angle smooth while hind margin with small teeth, apex spine-like; posterior margin of each lateral lobe with two concavities. Tegmina ovate, 2.3 times as long as its width, apex rounded (Figure 5C). Hindwing not reaching top of hind process of pronotum but slightly surpassing beyond top of hind femur (Figure 3A). Upper and lower margins of fore and mid femora undulate, with fine teeth; mid femur wider than tegmen and fore femur, middle femur distinctly narrowed from basal to distal side, and basal part thicker than distal part (Figure 5A, C). Hind femur about 2.5 times as long as wide, upper and lower margins dentate, outer side and upper side with a series of nodules; upper margin with a triangular protrusion before antegenicular, antegenicular isolated and long triangular, its apex nearly right angled, genicular denticle fingered extending backward and apex nearly quadrate (Figure 5B). Hind tibia distally slightly wider than basally, outer side with five to seven spines, inner side with for or five spines; first segment of hind tarsus 1.3-1.4 times (variable in different specimens) longer than third, third pulvillus about as long as second and slightly longer than first pulvillus, apices of all pulvilli sharp (Figure 5D). Subgenital plate short cone-shaped, apex bifurcate and bidentate (Figure 4D).

Body dark brown. Antenna brown and colour of distal segments darker; hindwings black; fore and mid femora and tibiae with three yellowish brown bands, bands of femora obscure; lower outside of hind femur black, centre of inner side of hind femur dark brown; hind tibia with two long yellowish brown bands.

\section{Female}

Slightly larger than male. Upper margin of fore femur arched, distinctly narrowed from basal to distal side; width of mid femur slightly narrower than width of tegmen, not narrowed or 
thicker from basal to distal area (Figure 3C). Ovipositor: length of upper valvulae about 4.0 times its width, outer margins of upper and lower valvulae with small saw-like teeth (Figure 4E). Posterior margin of subgenital plate: middle triangularly protruding, sometimes this protrusion folded inward, forming a basal concavity and a protrusion on both sides, and even the triangular protrusion invisible in ventral view (Figure 4F).

\section{Measurements}

Length of body (mm): $\widehat{\sigma} 6.0-6.8, q 6.8-7.8$; length of pronotum: $\$ 6.0-6.9$, $q$ 6.4-7.2; length of hind femur: $\widehat{\sigma} 3.4-3.8$, + 3.7-4.5.

\section{Type material}

Holotype (No. 15-0644, MFLU): $\sigma^{\lambda}$, Thailand, Chiang Rai $\left(20^{\circ} 19^{\prime} 43^{\prime \prime} \mathrm{N}, 99^{\circ} 51^{\prime} 48^{\prime \prime} \mathrm{E}, 402.3 \mathrm{~m}\right.$ altitude), 25 November 2014, collected by ZHA Ling-Sheng. Paratypes: $1 \delta^{\Uparrow} 2$ ㅇ (No. 15-0645, 15-0646, 15-0647, MFLU) $3{ }^{\Uparrow} 4$ ㅇ (HNU), same data as holotype.

\section{Diagnosis}

Thoradonta spiculobaoides sp. nov. is similar to T. spiculoba Hancock, 1912 (Zheng 2005) and T. dianguiensis Deng, Zheng and Wei 2006, It differs from the former by: (1) vertex only 1.5-1.6 times as wide as one eye (Figure 4A); (2) antenna inserted decidedly below lower margins of eyes (Figure 4B), length of longest segment six times its width; (3) upper margin of hind femur with a triangular protrusion before antegenicular, antegenicular isolated and long triangular (Figure 5B); (4) first segment of hind tarsus only 1.3-1.4 times as long as third, apices of all pulvilli sharp (Figure 5D); (5) female size distinctly smaller. It differs from the latter by: (1) body size decidedly smaller; (2) humeral angle obtusely angled (Figure $3 \mathrm{~B}$ ); (3) hind process of pronotum only slightly surpassing beyond top hind femora, never reaching one-third of hind tibia (Figure 3A-C); (4) upper margin of hind femur with a triangular protrusion before antegenicular, antegenicular isolated and long triangular (Figure 5B).

\section{Etymology}

The new species epithet is derived from Thoradonta spiculoba, which means it is similar to that species.

\section{Distribution}

Thailand (Chiang Rai).

\section{Discussion}

Both new species were collected in moist and stony environments near ponds in tropical rain forest of northern Thailand. Interestingly, they share striking similarities not only in some body structures, such as face, legs, male subgenital plate etc, but also with regard to their habitat. Without doubt their habitat environments have affected evolution of the shape of their bodies to a large degree.

Podgornaya (1994) indicates two forms of wings (brachypterous and macropterous) as occurring in $T$. spiculoba specimens collected from Vietnam. Similarly we find the length of the hind process of pronotum varying distinctly in Tetrix japonica (Bolívar) 
(Tetriginae) specimens collected in China. Generally, some important structures, such as width of vertex, lateral lobes of pronotum and surface of pronotum, vary in different species of the genus Thoradonta. So in identifying species of the genus, we should not simply regard lengths of wings or hind process of pronotum.

Unfortunately for the genus Thoradonta, there are only three nucleotide sequences, T. yunnana (EU414829, mtDNA-COI), T. spiculoba (EU368564, mtDNA-16S) and T. nodulosa (EU414812, mtDNA-COI), submitted in NCBI databases up to now. For studying the phylogeny of the genus, apart from morphological or behavioural characters, more studies on molecular systematics need be carried out in future.

\section{Disclosure statement}

No potential conflict of interest was reported by the authors.

\section{Funding}

This work was supported by the Modernization of Traditional Chinese Medicine Programme of Guizhou Province (No. [2012] 5008), the Agricultural Science and Technology Foundation of Guizhou Province (No. [2011] 3054), the Innovation Team Construction for Science and Technology of Guizhou Province (No. [2012] 4007), and the Science Research Foundation for Talents of Guizhou University (No. 201309).

\section{ORCID}

Ling-Sheng Zha (iD) http://orcid.org/0000-0003-4935-0725

Ting-Chi Wen (iD http://orcid.org/0000-0003-1744-5869

\section{References}

Blackith RE, Blackith RM. 1987. Tridactylids and Tetrigids (Orthoptera) from Sulawesi, Indonesia. Tijdschr Entomol. 130:1-10.

Bolivar I. 1887. Essai sur les Acridiens de la tribu des Tettigidae. Ann Soc Entomol Belg. 31:175-313. Deng WA, Zheng ZM, Wei SZ. 2006. Two new species of Scelimenidae from Yunnan and Guangxi, China (Orthoptera: Tetrigoidea). Acta Zootaxonomica Sinica. 31:369-372.

Deng WA, Zheng ZM, Wei SZ. 2007. Fauna of the Tetrigoidea from Yunnan and Guangxi. Nanning: Guangxi Science \& Technology Press; 458 pp.

Günther K. 1938. Revision der Acrydiinae (Orthoptera) II, Scelimenae spuriae. Stettiner Entomologische Zeitung. 99:117-148.

Hancock JL. 1909. Further studies of the Tetriginae (Orthoptera) in the Oxford University Museum. Trans R Entomol Soc Lond. 56:387-426.

Hancock JL. 1912. Tetriginae (Acridiinae) in the Agricultural Research Institute, Pusa, Bihar with the description of new species. India Department of Agriculture Memoirs - Entomological Series. 4 (2):131-160.

Hancock JL. 1915. Indian Tetriginae (Acrydiinae). Rec Indian Mus Calcutta. 11:80-82.

Ingrisch S. 2001. Orthoptera of the Nepal expeditions of Prof. J. Martens (Mainz). Senckenb Biol. 81:147-186.

Liang GQ, Zheng ZM. 1998. Fauna Sinica, Insecta, Volume 12, Orthoptera, Tetrigoidea. Beijing: Science Press; 278 pp.

Podgornaya LI. 1994. Notes on the genus Thoradonta Hancock (Orthoptera: Tetrigidae). Proc Zool Inst Russ Acad Sci St. Petersburg. 257:51-54. 
Shishodia MS. 1991. Taxonomy and zoogeography of the Tetrigidae (Orthoptera: Tetrigoidea) of north eastern India. Records of the Zoological Survey of India, Occasional Papers; p. 1-204.

Zheng ZM. 2005. Fauna of Tetrigoidea from Western China. Beijing: Science Press; 501 pp.

Zheng ZM, Liang GQ. 1991. On the genus Thoradonta Hancock from China (Orthoptera: Tetrigidae: Scelimeninae). Acta Entomol Sin. 34:453-457. 